\title{
Hemşirelik Öğrencilerinin İyi Hemşirenin Niteliklerine İlişkin Düşünceleri Eğitimin Başında ve Sonunda Değişiyor mu?
}

\author{
Aslıhan Akpınar®, Rahime Aydın Er®, Mine Şehiraltı®
}

Kocaeli Üniversitesi Tıp Fakültesi, Tıp Tarihi ve Etik Anabilim Dalı, Kocaeli, Türkiye

Aslıhan Akpınar, Dr. Öğr. Üyesi Rahime Aydın Er, Dr. Öğr. Üyesi Mine Şehiraltı, Doç. Dr.

09-12 Nisan 2015 tarihleri arasında Ankara'da yapılan 8. Uluslararası Katııımlı Türkiye Biyoetik Derneği Kongresi'nde sunulmuş ve Kongre Kitabı'nda basılmıştır. (Ankara, 2016: 127-135)

Illetişim:

Dr. Öğr. Üyesi Aslihan Akpınar Kocaeli Üniversitesi Tıp Fakültesi, Tip Tarihi ve Etik Anabilim Dalı, Kocaeli, Türkiye Tel: +902623037055 E-Posta:aslyakcay@yahoo.com

Gönderilme Tarihi : 03 Temmuz 2017

Revizyon Tarihi : : 07 Eylül 2017

Kabul Tarihi : : 09 Eylül 2017
ÖZET

Amaç: Çalışmada hemşirelik eğitimine yeni başlayan öğrencilerin iyi hemşirenin niteliklerine ilişkin düşüncelerinin mezuniyet aşamasına geldiklerinde değişip değişmediği ve değiştiyse ne yönde değiştiğinin belirlenmesi amaçlanmıştır.

Hastalar ve Yöntem: Çalışma 2010/2011 ve 2013/2014 akademik yılında bir sağlık yüksekokulunun hemşirelik bölümünde yürütüldü. Hemşirelik eğitimine başlayan 88 birinci sınff öğrencisi çalışmaya katılmak üzere davet edildi. Öğrencilere 'Sizce iyi bir hemşirenin sahip olması gereken özellikler ne olmalıdır?' sorusunu içeren çalıșma formu dağıııldı. Aynı çalıșma formu öğrenciler son sınıftayken tekrar dağıtıldı $(n=77)$. Ögrrenciler tarafından ifade edilen benzer nitelikler araştırmacılar tarafından bir araya getirilerek gruplandırdı. Elde edilen nitelikler (a) Kişilerarası ilişkiler ve iletişim, (b) Kişisel bütünlüğü korumak, (c) Mesleki bütünlüğü korumak, (d) Mesleki bilgi ve yeterlik için gerekli nitelikler olarak dört başık altında toplandı. Belirlenen nitelikler ile öğrencilerin sınffı arasındaki ilişki ki kare testi ile analiz edildi.

Bulgular: Çalışmaya $82(\% 93,1)$ birinci ve $61(\% 79,2)$ dördüncü sınıf öğrencisi katıldı. Iyi hemşirenin sahip olması gereken niteliklere ilişkin öğrenciler birinci sınıfta 594, son sınıfta 387 olmak üzere 981 nitelik ifade etti. Öğrenciler hem birinci sınıfta hem de son sınıfta iyi bir hemşireyi en sık (birinci sınıf $\% 52,4$; dördüncü sınıf $\% 82,0$ ) 'mesleğinde yeterli' özelliğgi ile tanımlamıştı. Bununla birlikte her iki sınıfta da öğrencilerin en fazla (birinci sınıf \% 49,0 ; dördüncü sınıf $\% 42,6$ ) ifade ettiği nitelikler 'kișilerarass ilişkiler ve iletiş̧̇m' için gerekli niteliklerdi. Birinci sınff öğrencileri 'sayglıl', 'fedakâr', 'sabırlı','maddi değerleri ön planda tutmayan' ve 'mesleğine sadık' niteliklerini, dördüncü sınıfta ise 'empati yapabilen', 'ekip çalışması yapabilen', 'sorumluluk sahibi,', 'mesleğinde yeterli', 'mesleğini geliştiren' ve 'profesyonel' niteliklerini daha sık ifade etti $(\mathrm{p}<0.05)$.

Sonuç: Öğrencilerde hemşirelik eğitimin sonunda empati, ekip üyeleriyle işbirliği yapma, mesleğinde yeterli ve sorumluluk sahibi olma gibi mesleğin uygulanmasına yönelik niteliklere vurgu artarken, eğitimin başında sıkça vurgulan kişilerarası ilişkilere ilişkin bazı niteliklere vurgunun azaldı̆̆ı gözlenmiş̧tir. Farklı etik eğitim yöntemleri, 'iyi hemşire' kavramı iç̧in gerekli olan niteliklere verilen önemin devam etmesi, kazanılması ve uygulamaya aktarılabilmesi için öğrencilere olanak sağlayabilir.

Anahtar sözcükler: Tıp etiği, profesyonellik, hemşirelik eğitimi, hemşirelik öğrencileri

DO THE OPINIONS OF NURSING STUDENTS TOWARDS THE ATTRIBUTES OF A GOOD NURSE CHANGE WHEN THEY ARE IN THE FIRST AND FOURTH YEAR?

ABSTRACT

Purpose/Aim: We aimed to determine the opinions of nursing students when they are in their first and fourth-year towards the'attributes of a good nurse', and whether and how their views were changed.

Patients and Methods: This study was conducted in the nursing department of a vocational school of health. In 2010/11 academic year, 88 first-year students were asked the following open-ended question: 'What, in your opinion, are the attributes of a good nurse?' The same question was asked to the students when they were in the fourth-year ( $n: 77)$. The attributes that had been specified by the students were classified afterwards into four categories: (a) Interpersonal relations and communication, (b) the sustaining of personal integrity, (c) the sustaining of professional integrity, (d) scientific knowledge and competence. The relationship between the students' years of study and the attributes they specified was analyzed by a chi-square test.

Results: 82 first year students and 61 fourth year students participated in the study. Students stated 594 attributes of a good nurse in the first-year and 387 in the fourth-year. They frequently $52.4 \%, 82.0 \%$ ) described a good nurse as having 'professional competence' both in the first and fourth year. However, when they were in the first and fourth-year, they mostly (49.0\% and $42.6 \%)$ described a good nurse with attributes related to 'interpersonal relations and communication'. Students placed a greater emphasis on the attributes of 'respectful', 'altruistic,' 'patient', 'not attaching importance to material values', and 'loyalty to nursing' in first year, and attributes of 'empathy', able to work in a team', 'responsibility' competence' and 'professional' in fourth year.

Conclusion: While the emphasis on the attributes that are related to good nursing practices such as 'able to work in a team', 'competency' and 'responsibility' has increased; some attributes related to interpersonal relations and communication were decreased. Different educational methods could ensure maintaining, acquiring, and implementing important attributes for'a good nurse'.

Keywords: Medical ethics, professionalism, nursing education, nursing students 
G ünümüzde nitelikli sağlık hizmeti sunabilmenin temel koşullarından biri, alanında uzmanlaşmış sağlık profesyonellerinin varlığıdır (1). Hemşireliğin ise profesyonelleşme yolunda ilerlemeye devam eden bir meslek olduğu kabul edilmektedir. Hemşirenin yıllar boyunca doktorun yardımcısı olarak görülmesi, emre itaatin 'iyi hemşire'den beklenen nitelikler arasında önemli bir yer tutmasına neden olmuştur $(2,3)$. Özellikle 1980'lerden sonra hemşirelik meslekleşme sürecinde belirgin bir ilerleme sağlamış, daha profesyonel ve kendi kararlarını alabilen bir meslek haline gelmiştir (4). Hemşirelik modern bir mesleğe dönüşmeye devam ettikçe iyi hemşireden beklenen nitelikler de değişmiştir. Uluslararası Hemşireler Birliği ve Amerikan Hemşireler Derneği tarafından hazırlanan modern hemşirelik etik kodlarına göre; hemşireden emirlere itaat etmesi yerine özerkliğini koruması, diğer profesyonellerle işbirliği yapması beklenmektedir $(5,6)$. Bununla birlikte hemşireden beklenen diğer davranış özellikleri; savunuculuk ve hesap verilebilirliktir (2). Bu davranışları geliştirebilmiş iyi hemşirenin sahip olması gereken niteliklerin neler olduğu, profesyonelleşme sürecinde nasıl kazandırılacağı ve nasıl ölçüleceği ile ilgili çalışmaların yürütülmesi önem taşımaktadır.

İyi hemşirenin niteliklerini belirleme amacıyla yapılan çalışmalar daha çok hemşirelik becerileri ile ilgilidir ve hastaların iyi hemşireyi algılamaları araştırılmıştır (7-9). Hemşirelerin perspektifinden iyi hemşirenin niteliklerinin tanımlanmasına yönelik az sayıda çalışma bulunmaktadır (10-13). Hemşirelik eğitimi hemşirelikte profesyonellik bileşenlerinin merkezinde yer almaktadır (4). Eğitimin en önemli paydaşları olan öğrencilerin iyi hemşireye ilişkin görüşleri, profesyonellik eğitiminin planlanmasına ve yürütülmesine önemli katkı sağlayabilir. Bu çalışmada hemşirelik eğitimine yeni başlayan öğrencilerin iyi hemşirenin niteliklerine ilişkin düşüncelerinin (13) mezuniyet aşamasına geldiklerinde değişip değişmediği ve değiştiyse ne yönde değiştiğinin belirlenmesi amaçlanmıştır.

\section{Gereç ve yöntem}

Kesitsel tanımlayıc tipte olan çalışma 2010/2011 ve 2013/2014 akademik yılında Kocaeli Üniversitesi Sağlık Yüksekokulu Hemşirelik Bölümü'nde yürütüldü. Çalışmanın 2010/2011 yılında hemşirelik eğitimine yeni başlayan 88 birinci sınıf öğrencisi ile yürütülen kısmı, aynı yıl dördüncü sınıfta olan öğrencilerle karşılaştırılarak yayımlanmıştı (13). Bu çalışmada, aynı öğrencilerin düşüncelerinde değişiklik olup olmadığını anlamak amacıyla 2013/2014 akademik yılında dördüncü sınıfa gelmiş olan öğrenciler çalışmaya katılmak üzere davet edildi. Okul yönetiminden alınan idari izin ile yürütülen çalışmada öğrencilerin gönüllülüğünü sağlamak amacıyla okulda görev yapmayan araştırmacılardan biri tarafından çalışmanın amacı hakkında bilgilendirilen öğrencilere ('Cinsiyetiniz' ve 'Sizce iyi bir hemşirenin sahip olması gereken özellikler ne olmalıdır?') sorularını içeren çalışma formu dağıtıldı $(n=77)$. Birinci sınıfta da çalışmaya katılmış olan ve tekrar katılmaya gönüllü olan öğrencilerin çalışma formunu doldurduktan sonra masa üstüne bırakılan kapalı kutuya atmaları istendi.

Öncelikle öğrenciler tarafından ifade edilen niteliklerin tümü sıralandı ve benzer nitelikler araştırmacılar tarafından bir araya getirilerek gruplandırıldı. Elde edilen nitelikler iki araştırmacı tarafından daha önceki çalışmalarda $(13,14)$ kulIanılan yöntemle (a) Kişilerarası ilişkiler ve iletişim için gerekli nitelikler (b) Kişisel bütünlüğü korumak için gerekli nitelikler (c) Mesleki bütünlüğü korumak için gerekli nitelikler (d) Mesleki bilgi ve yeterlik için gerekli nitelikler olarak dört ana başlık altında toplandı. Üçüncü araştırmacı tarafından nitelik gruplandırmaları kontrol edilerek birbirine uyumsuz olanlar belirlendi. Daha sonra üç araştırmacının ortak kararıyla bu niteliklerin hangi başlıkta yer alacağı ile ilgili görüş birliğine varıldı. Ana başlıkların öncelik sırasının belirlenmesinde öğrenciler tarafından ifade edilen toplam nitelik sayısı olan 981; sınıflarda gruplarda yer alan niteliklerin kaç kez ifade edildiğinin belirlenmesinde sınıfın öğrenci sayısı (birinci sınıf 82, dördüncü sınıf 61) temel alınarak yüzde dağılımları hesaplandı. Belirlenen nitelikler ile öğrencilerin sınıfı arasındaki ilişki ki-kare testi ile analiz edildi.

\section{Bulgular}

Çalışmaya $82(\% 93,1)$ birinci sınıf ve $61(\% 79,2)$ dördüncü sınıf öğrencisi katıldı. Birinci sınıf öğrencilerinin $\% 57,1^{\prime} \mathrm{i}$, dördüncü sınıf öğrencilerinin \%42,9'u kadındı.

İyi hemşirenin sahip olması gereken niteliklere ilişkin öğrenciler birinci sınıfta 594, son sınıfta 387 olmak üzere toplam 981 nitelik ifade etti. Öğrenciler hem birinci sınıfta hem de son sınıfta iyi bir hemşireyi en sık (birinci sınıf $\% 52,4$; dördüncü sınıf \%82,0) 'mesleğinde yeterli' özelliği ile tanımlamıştı. Bununla birlikte her iki sınıfta da öğrencilerin en fazla (birinci sınıf \%49,0; dördüncü sınıf \%42,6) ifade ettiği nitelikler 'kişilerarası ilişkiler ve iletişim' için gerekli niteliklerdi (Tablo 1).

\section{Kişilerarası ilişkiler ve iletişim için gerekli nitelikler}

Bu grupta kişilerarası ilişkiler, hemşire-hasta ilişkisi, sözlü ve sözsüz iletişim ile ilgili nitelikler yer almaktadır. Öğrencilerin hemşirelik eğitiminin başında ve eğitimin sonunda ifade ettikleri niteliklerin yarısı bu grupta yer aldı 
(Tablo 1). Birinci sınıf öğrencileri bu grupta en fazla 'güleryüzlü' niteliğini ifade ederken, dördüncü sınıf öğrencileri en fazla 'empati yapabilen' niteliğini ifade etti. İki sınıf öğrencileri bu grupta yalnızca 'iyi iletişim kurabilen' niteliğini benzer oranda ifade etti. Bunun dışında 'saygılı' $(p=0,032)$, 'fedakâr' $(p=0,002)$ ve 'sabırlı' $(p<0,001)$ niteliklerini birinci sınıf öğrencileri, 'empati yapabilme' $(p=0,001)$ niteliğini dördüncü sınıf öğrencileri istatistiksel açıdan anlamlı şekilde daha fazla ifade etti (Tablo 2).

\section{Mesleki bütünlüğü korumak için gerekli nitelikler}

Hemşirenin topluma ve mesleğe karşı sorumluluklarını ifade eden nitelikler bu başlık altında toplandı. Öğrenciler hem birinci hem dördüncü sınıfta iyi bir hemşirenin bu grupta yer alan nitelikler arasından en fazla 'sorumluluk

Tablo 1. Öğrencilerin iyi hemşireye ilişkin belirttikleri niteliklerin sıniflandırıması

\begin{tabular}{lcccc} 
Nitelik grubu & \multicolumn{2}{c}{ 1. sınıf } & \multicolumn{2}{c}{ 4. sınıf } \\
\hline & $\boldsymbol{n}$ & $\%$ & $\boldsymbol{n}$ & $\%$ \\
\hline $\begin{array}{l}\text { Kişilerarası ilişkiler ve iletişim için } \\
\text { gerekli nitelikler }\end{array}$ & 291 & 49,0 & 165 & 42,6 \\
$\begin{array}{l}\text { Mesleki bütünlüğü korumak için } \\
\text { gerekli nitelikler }\end{array}$ & 110 & 18,5 & 105 & 27,1 \\
$\begin{array}{l}\text { Mesleki bilgi ve yeterlik için gerekli } \\
\text { nitelikler }\end{array}$ & 93 & 15,7 & 90 & 23,3 \\
$\begin{array}{l}\text { Kişisel bütünlüğü korumak için } \\
\text { gerekli nitelikler }\end{array}$ & 100 & 16,8 & 27 & 7,0 \\
$\begin{array}{l}\text { Toplam } \\
\text { Melam }\end{array}$ & $\mathbf{5 9 4}$ & $\mathbf{1 0 0}$ & $\mathbf{3 8 7}$ & $\mathbf{1 0 0}$
\end{tabular}

Tablo 2. Öğrencilerin kişilerarası ilişkiler ve iletişim başlı̆ı altında ifade ettikleri nitelikler

\begin{tabular}{lccccc} 
Nitelik* & \multicolumn{2}{c}{ 1. sını } & \multicolumn{2}{c}{ 4. sınıf } & istatistiksel anlamlıık \\
\hline & $\boldsymbol{n}$ & $\%$ & $\boldsymbol{n}$ & $\%$ & \\
\hline Güleryüzlü & 40 & 48,8 & 22 & 36,1 & \\
Sabırlı & 40 & 48,8 & 11 & 18,0 & $\chi^{2}=14,413 ; p=0,000$ \\
Hoşgörülü & 32 & 39,0 & 22 & 36,1 & \\
İnsancıl & 31 & 37,8 & 16 & 26,2 & - \\
Hastasını & 24 & 29,3 & 10 & 16,4 & - \\
önemseyen & & & & & \\
Saygılı & 24 & 29,3 & 9 & 14,8 & $\chi^{2}=4,151 ; p=0,032$ \\
Şefkatli & 24 & 29,3 & 15 & 24,6 & - \\
Fedakâr & 23 & 28,0 & 5 & 8,2 & $\chi^{2}=8,755 ; p=0,002$ \\
İi iletişim & 23 & 28,0 & 20 & 32,8 & \\
kurabilen & & & & & \\
Empati & 12 & 14,6 & 23 & 37,7 & $\chi^{2}=10,072 ; p=0,001$ \\
yapabilen & & & & & \\
\hline *10 ve daha fazla öğrenci tarafından ifade edilen nitelikler belirtilmiştir.
\end{tabular}

sahibi' niteliğine sahip olması gerektiğini ifade etti. Öğrenciler birinci sınıfta 'maddi değerleri ön planda tutmayan' niteliğini $(p=0,017)$, dördüncü sınıfta ise 'sorumluluk sahibi' $(p=0,031)$ ve 'ekip çalışması yapabilen' $(p=0,015)$ niteliklerini anlamlı şekilde daha fazla ifade ettiler. 'Mesleğini severek yapan' ve 'adaletli' nitelikleri iki sınıfta da öğrenciler tarafından benzer oranda ifade ettiler. (Tablo 3). 'Hemşireliği bağımsız bir meslek olarak gören' niteliği birinci sınıf öğrencileri tarafından az sayıda da olsa $(n=3)$ ifade edilen ve bu grupta yer alan başka bir nitelikti.

\section{Mesleki bilgi ve yeterlik için gerekli nitelikler}

Her iki sınıf öğrencileri tarafından bu grupta en fazla ifade edilen nitelik 'mesleğinde yeterli' olmakla birlikte bu nitelik dördüncü sınıf öğrencileri tarafından daha fazla ifade edilmişti $(p<0,001)$. İstatistiksel açıdan anlamlı farklııık bulunmamakla birlikte yine dördüncü sınıf öğrencileri tarafından 'kendini mesleki anlamda geliştiren' niteliği sıklıkla ifade edilen diğer bir nitelikti (Tablo 4). Bu grupta yer alan diğer nitelikler 'araştırmacı', 'bilimsel düşünebilen' ve 'disiplinli/planlı/programlı' nitelikleriydi.

\section{Kişisel bütünlüğü korumak için gerekli nitelikler}

Öğrencilerin mesleği, hastaları veya diğer kişileri vurgulayarak ifade etmedikleri ve çekirdek eğitim programlarında

Tablo 3. Öğrencilerin mesleki bütünlüğü korumak için gerekli nitelikler başı̆ı̆ı altında ifade ettikleri nitelikler

\begin{tabular}{lccccc} 
Nitelik* & \multicolumn{2}{c}{ 1. sınıf } & \multicolumn{2}{c}{ 4. sınıf } & istatistiksel anlamlıIı \\
\hline & $\boldsymbol{n}$ & $\%$ & $\boldsymbol{n}$ & $\%$ & \\
\hline Sorumluluk sahibi & 33 & 40,2 & 35 & 57,4 & $\chi^{2}=4,117 ; p=0,031$ \\
$\begin{array}{l}\text { Mesleğini severek } \\
\text { yapan }\end{array}$ & 30 & 36,6 & 21 & 34,4 & - \\
$\begin{array}{l}\text { Adaletli } \\
\text { Ekip çalışması }\end{array}$ & 12 & 14,6 & 14 & 23,0 & - \\
yapabilen & 14,6 & 19 & 31,1 & $\chi^{2}=5,618 ; p=0,015$ \\
$\begin{array}{l}\text { Maddi değerleri } \\
\text { ön planda tutmayan }\end{array}$ & 10 & 12,2 & 1 & 1,6 & $\chi^{2}=5,489 ; p=0,017$ \\
*10 ve daha fazla öğrenci tarafindan ifade edilen nitelikler belirtilmiştir.
\end{tabular}

Tablo 4. Öğrencilerin mesleki bilgi ve yeterlik için gerekli nitelikler başlığı altında ifade ettikleri nitelikler

\begin{tabular}{lccccc} 
Nitelik $^{*}$ & \multicolumn{2}{c}{ 1. sını } & \multicolumn{2}{c}{ 4. sınıf } & istatistiksel anlamlılık \\
\hline & $\boldsymbol{n}$ & $\%$ & $\boldsymbol{n}$ & $\%$ & \\
\hline $\begin{array}{l}\text { Mesleğinde } \\
\text { yeterli }\end{array}$ & 43 & 52,4 & 50 & 82,0 & $\chi^{2}=13,412 ; p<0,001$ \\
$\begin{array}{l}\text { Mesleki anlamda } \\
\text { geliştiren }\end{array}$ & 15 & 18,3 & 18 & 29,5 & - \\
\hline
\end{tabular}

*10 ve daha fazla öğrenci tarafından ifade edilen nitelikler belirtilmiştir. 
da vurgulanmayan nitelikler bu başlık altında toplandı. Bu gruptaki nitelikler geniş bir dağılım göstermekteydi. Öğrenciler birinci sınıfta iken dördüncü sınıfa oranla bu grupta yer alan daha fazla nitelik ifade etmişti. Birinci sınıfta onar öğrenci $(\% 12,2)$ tarafından belirtilen 'güvenilir', 'kendine güvenen' ve 'sakin' nitelikleri gibi az sayıda nitelik yanında bu grupta çoğunlukla 'ahlaklı', 'çağdaş,' 'kültürlü', 'kendisiyle barışık', 'vatansever' gibi birer öğrenci tarafından ifade edilen ve öğrencilerin hayat görüşlerini yansıttığını düşündügümüz nitelikler bulunmaktaydı.

\section{Tartışma}

İyi hemşirenin niteliklerine ilişkin görüşlerini belirlemek amacıyla öğrenciler ile hemşirelik eğitiminin başında ve sonunda yürüttüğümüz çalışmamızın sonuçlarına göre, öğrencilerin ifade ettikleri niteliklerin yarısı 'Kişilerarası ilişkiler ve iletişim' için gerekli nitelikler arasında yer almaktadır. Bu sonuç profesyonel hemşire nitelikleri arasında iletişimin önemli bir nitelik olduğu görüşü ile uyumludur (15). 'Etkili kişilerarası iletişim kurabilme' aynı zamanda, Hemşirelik Ulusal Çekirdek Eğitim Programının hemşirelik lisans eğitim hedefleri arasındadır (16). Yapılan çalışmalarda hastaların (7-9,17-20), akademisyenlerin (21), hemşirelerin $(10,11)$ ve öğrenci hemşirelerin (22-23) iyi hemşireye ilişkin ifade ettikleri nitelikler de iletişim becerilerine vurgu yapmaktadır. Öğrenci hemşirelerin son sınıfta iletişim becerilerinin ve empati düzeylerinin yükseldiği belirtilmektedir (24). Öğrencilerin dördüncü sınıfta 'iyi iletişim kurabilen' niteliği ile birlikte 'empati yapabilen' niteliğini vurgulamalarının, hemşirelik eğitiminin içerisinde empatiye kurumsal ve uygulamalı olarak yer verilmesi nedeniyle olduğu düşünülebilir. Öğrencilerin birinci sınıfta daha çok ifade ettikleri 'sabırlı', 'saygılı' ve 'fedakâr' nitelikleri sağlık profesyonellerinden beklentilere ilişkin yapılan çalışma sonuçlarında hastaların önem verdiği nitelikler arasındadır $(17,18,25)$. Modern hemşirelik etik kodlarında yer almayan fedakâr niteliğindeki azalma makul bulunabilirken, hasta beklentileri arasında da sıkça yer alan sabırlı ve saygılı niteliklerinin (7-9,17-20) eğitim ile azalmış olması düşündürücüdür.

Son sınıfta daha sık olmakla birlikte öğrenciler hem birinci sınıfta hem de son sınıfta iyi hemşireyi 'mesleğinde yeterli' özelliği ile tanımlamışlardı. Yapılan çalışmalar yanında $(8,17-19)$ profesyonellik tanımında da içkin olan mesleki yeterliliğe verilen bu önemin olumlu olduğu düşünülmektedir. Hemşirelik etik kodlarında $(5,6)$ vurgulanan mesleki gelişimi sağlama ve sürekli kılma ile hemşirenin profesyonelleşmesinde önemli görülen 'alana özel araştırma yapmak' özelliğine (26) uygun olarak dördüncü sınıf öğrencileri 'kendini mesleki anlamda geliştiren' niteliğine daha fazla önem vermekteydi. Bu sonuca dayanarak, hemşirelik eğitiminin öğrencilerin mesleki gelişimin önemini kavrayabilmesinde başarılı olduğu söylenebilir.

Öğrenciler birinci ve son sınıfta 'mesleki bütünlüğü korumak için gerekli nitelikler' başlığı altında iyi hemşireye ilişkin en sık'sorumluluk sahibi' niteliğini bildirmişti. Bununla birlikte öğrenciler bu nitelikle birlikte 'ekip çalışması yapabilen' niteliğini hemşirelik eğitimin sonunda daha fazla ifade etmişti. Bu niteliklerin eğitim ve özellikle üst sınıfta ağırlık kazanan klinik uygulama yoluyla geliştirildiği düşünülebilir. Öğrenciler hemşirelik eğitiminin başında ve sonunda benzer oranda 'mesleği severek yapan' niteliğini vurgulamıştı. Mesleğini severek yapan hemşirelerin mesleki profesyonelliklerinin daha yüksek olduğu belirtilmektedir (4). Dolayısıyla öğrencilerin son sınıfta da mesleğini severek yapmaya önem vermesi mesleki profesyonellikleri açısından olumlu olabilir. Öğrenciler hemşirelik eğitiminin başında 'maddi değerleri ön planda tutmayan' niteliğine daha fazla önem vermişti. 'Maddi değerleri ön planda tutmama' niteliği, tıbbın önemli erdemlerinden biri olan 'kendi çıkarlarını hastanın çıkarlarından üstün tutmamak' erdemiyle yakından ilişkilidir. Yine bir işin bir meslek olarak kabul edilmesi için gereken özelliklerden birisi 'ekonomik faydanın ötesinde işe olan bağlılık'tır (27). Öğrencilerin mezun olmak üzereyken bu niteliği daha az vurgulamalarını açıklayabilecek çalışmalara intiyaç bulunmaktadır.

Öğrencilerin ifade ettikleri nitelikler çoğunlukla hemşireliğin bağımsız bir meslek olarak tanımlanabilmesi için gerekli bulunan davranış özelliklerini karşılamaktadır. Örneğin önemli oranda öğrencinin ifade ettiği "ekip çalışması yapabilme" niteliği, diğer profesyonellerle işbirliği yapma davranışına tamamen uygundur. Benzer şekilde "sorumluluk sahibi olma" ve "mesleğinde yeterli olma" gibi nitelikler, hesap verilebilirlik özelliğinin ifadesi olarak düşünülebilir. "Adaletli", "insancıl", "hastasını önemseyen" nitelikleri ise eğitimde öğrencilerin hasta savunuculuğunu üstlenme davranışını gösterebilmeleri için rehberlik sağlayabilir. Ancak bağımsız bir hemşirelik mesleği için gerekli bulunan özerkliğin korunması davranışlarına yönlendirecek niteliklerin çalışmaya katılan öğrenciler tarafından çok az ifade edildiği görülmüştür. Bu durum, eğitimde mesleğin bu yönünü vurgulayıcı uygulamaların yararlı olacağını düşündürmektedir.

\section{Sonuç}

Çalışmamızın amacı aynı öğrencilerin görüşlerinin değişimini değerlendirmek olmakla birlikte çalışma formları isimsiz toplandığından öğrencilerdeki bireysel değişimi 
değerlendirmek mümkün olmamıştır. Bununla birlikte çaIışmamızda dikkate değer sonuçlara ulaşılmıştır.

Bu çalışmaya katılmış bulunan dördüncü sınıf öğrencileri, 2010/2011 akademik yılında çalışmaya katılan dördüncü sınıf öğrencileriyle çoğunlukla benzer nitelikler ifade etmişlerdir. Ancak; "güleryüzlü", "hoşgörülü", "şefkatli", "ekip çalışması yapabilen" ve "mesleğinde yeterli" nitelikleri önceki dördüncü sınıf öğrencilerine oranla (13) daha

\section{Kaynaklar}

1. Ulusoy H, Tokgöz DM. Hekim ve hemşirelerin ekip çalışmasına ilişkin görüşleri. Pam Tıp Derg 2009;2:55-61.

2. Begley AM. On being a good nurse: reflections on the past and preparing for the future. Int J Nurs Pract 2010;16:525-32. [CrossRef]

3. Rchaidia L, Dierckx de Casterle B, Verbeke G, Gastmans C. Oncology patients' perceptions of the good nurse: an explorative study on the psychometric properties of teh Flemish adaptation of the Care-Q instrument. J Clin Nurs 2011;21:1387-400. [CrossRef]

4. İşçi N. Hastanede Çalışan Hemşirelerin Mesleki Profesyonellik Düzeyinin Tıbbi Hata Yapma Eğilimleri Üzerine Etkisi. Atatürk Üniversitesi Sağlık Bilimleri Enstitüsü Yüksek Lisans Tezi, Erzurum, 2015.

5. International Council of Nurses. The ICN Code of Ethics for Nurses. 2012. Available from: https://www.icn.ch/sites/default/files/inlinefiles/2012_ICN_Codeofethicsfornurses_\%20eng.pdf

6. American Nurses Association. Code of Ethics for Nurses with Interpretive Statements. US: Nursesbooks.org. 2015. Retrieved March 24, 2017 from http://www.nursingworld.org/MainMenuCategories/ EthicsStandards/CodeofEthicsforNurses/Code-of-Ethics-For-Nurses. html

7. McCabe C. Nurse-patient communication: an exploration of patients' experiences. J Clin Nurs 2004;13:41-9.

8. Brady M. Hospitalized children's views of the good nurse. Nurs Ethics 2009;16:543-60. [CrossRef]

9. Randall D, Hill A. Consulting children and young people on what makes a good nurse. Nurs Child Young People 2012;24:14-9. [CrossRef]

10. Armstrong $A E$, Parsons $S$, Barker PJ. An inquiry into moral virtues, especially compassion, in psychiatric nurses: findings from a Delphi study. J Psychiatr Ment Health Nurs 2000;7:297-305.

11. Fagerström L. The dialectic tension between 'being' and 'not being' a good nurse. Nurs Ethics. 2006;13:622-32. [CrossRef]

12. Catlett S, Lovan SR. Being a good nurse and doing the right thing: a replication study. Nurs Ethics 2011;18:54-63. [CrossRef]

13. Aydin Er R, Sehiralti M, Akpinar A. Attributes of a good nurse. Nurs Ethics. 2017;24:238-50. [CrossRef] yüksektir. Bu öğrencilerin birinci sınıfta da aynı nitelikleri önemli görmeleri, bireysel özelliklerin iyi hemşirenin niteliklerini benimseme açısından fark yarattığı şeklinde yorumlanabilir. Ancak iki farklı akademik yılda dördüncü sınıf öğrencileri ile çalışmaların yürütülmüş olması, eğitimde bu niteliklere önem veren uygulamalarda olumlu yönde değişiklik olduğunu da düşündürebilir. Ayrıntılı belirleme için daha ileri araştırmalara ihtiyaç olduğu düşünülmektedir.

14. Sehiralti M, Akpinar A, Ersoy N. Attributes of a good physician: what are the opinions of first-year medical students? J Med Ethics 2010;36:121-5. [CrossRef]

15. Sabancıoğulları S, Doğan S. Profesyonel kimlik gelişimi ve hemşirelik. Anadolu Hemşirelik ve Sağlık Bilimleri Dergisi 2012;15:275-82.

16. Hemşirelik Ulusal Çekirdek Eğitim Programı. 2014. Erişim: http:// www.hemed.org.tr/index.php?option=com_content\&task=view\&id $=547 \&$ Itemid $=178$

17. Erbil N, Şenkul A, Sağlam Y, Ergül N. Jinekolojik muayene öncesinde Türk kadınların anksiyete seviyeleri ve muayeneye ilişkin tutumlarının belirlenmesi. Uluslararası İnsan Bilimleri Dergisi 2008;5:1-13.

18. Rchaidia L, Dierckx de Casterlé B, De Blaeser L, Gastmans C. Cancer patients' perceptions of the good nurse: a literature review. Nurs Ethics 2009;16:528-42. [CrossRef]

19. Altay B, Kefeli B. Jinekolojik muayeneye gelen kadınların anksiyete düzeyi ve etkileyen bazı faktörler. Dokuz Eylül Üniversitesi Hemşirelik Yüksekokulu Elektronik Dergisi 2012;5:134-41. http://hdl.handle. net/20.500.12397/4623

20. Rush B, Cook J. What makes a good nurse? Views of patients and carers. Br J Nurs 2006;15:382-5. [CrossRef]

21. Sartorio NA, Pavone Zoboli EL. Images of a'good nurse' presented by teaching staff. Nurs Ethics 2010;17:687-94. [CrossRef]

22. Davis AJ, Hershberger A, Ghan LC, Lin JY.The good nurse: descriptions from the People's Republic of China. J Adv Nurs 1999;15:829-34.

23. Lundberg PC, Boonprasabhai K. Meanings of good nursing care among Thai female last-year undergraduate nursing students. J Adv Nurs 2001;34:35-42.

24. Tutuk A, AI D, Doğan S. Hemşirelik öğrencilerinin iletişim becerisi ve empati düzeylerinin belirlenmesi. CÜ Hemş YO Derg 2002;6:36-41.

25. Cetin $M, U$ çar $M$, Güven $T$, Ataç $A$, Ozer $M$. What do patients expect from their physicians? Qualitative research on the ethical aspects of patient statements. J Med Ethics 2012;38:112-6. [CrossRef]

26. Wynd CA. Current factors contributing to professionalism in nursing. J Prof Nurs 2003;19:251-61.

27. Ayaz Ö. Hekim, Hemşire ve Sağlık Yöneticilerinin Meslekleşme Düzeylerinin Değerlendirilmesi. Beykent Üniversitesi Sosyal Bilimler Enstitüsü Yüksek Lisans Tezi, İstanbul, 2010. 